\title{
Enterprise Architecture Integration in E-government
}

\author{
Marijn Janssen \\ School of Technology, Policy and \\ Management \\ Delft University of Technology \\ Jaffalaan 5, NL-2600 GA, Delft \\ The Netherlands \\ Tel. $+31(15) 2781140$ \\ Fax. $+31(15) 2783741$ \\ Marijni@tbm.tudelft.nl
}

\author{
Anthony Cresswell \\ Center for Technology in Government \\ University at Albany-SUNY \\ 187 Wolf Road, Suite 301 \\ Albany, NY 12205 \\ Tel: (518) 442-3766 \\ Fax: (518) 442-3886 \\ tcresswell@,ctg.albany.edu
}

\begin{abstract}
Achieving goals of better integrated and responsive government services requires moving away from stand alone applications toward more comprehensive, integrated architectures. As a result there is mounting pressure to move from disparate systems operating in parallel toward a shared architecture designed to support information exchange and cross-agency business processes.

This paper presents a simulation-based approach to designing and evaluating ways to achieve such sharing. This approach support the mapping EAI technology on the business processes needing to be supported and is based on technology, business process and stakeholder-level components. Discreteevent simulation and animation combined with activity-based costing is used to evaluate the benefits of the proposed EAI solution. The results provide insight into the implications of EAI, used to support information sharing and integration of service processes. In this way the benefits and implications of the EAI approach can be assessed.
\end{abstract}

\section{Introduction}

High quality experiences with responsive, integrated private sector information systems are leading citizens to expect the same from public bodies and agencies [9]. As a result, citizens and businesses are demanding faster delivery of public services and better insight into the status of their requests. Effective service delivery requires the sharing of information among information systems of public agencies and requires cross-agency business processes. The integration of disparate systems has become one of the prime concerns. An important issue, in the short term, plaguing the government on-line agenda is the debate as to how best to proceed with integration. Existing systems are typically build-using architectures that do not readily support enterprise-wide integration, thus requiring the development of the new architecture to link on-line government [1]. The integration aim of the Dutch government, for example, is that constituents should provide data only once and all government agencies should reuse this data by 2007 [7]. This can only be accomplished when government agencies share data and reuse them in their processes.

Enterprise Application Integration (EAI) is an emerging approach to architecture design that aims at linking up such previously separated and isolated systems to give them greater leverage [12]. EAI is typically a backroom technology [22]. Its support the processes within an organization and is not directly visible to the general staff or its clients and stakeholders.

At this stage, little is known about the impacts of EAI on the performance of actual business processes. Research-to-date has been focused almost exclusively on the technology [22], although it is often argued that organizational issues and stakeholder interests should be addressed as well [26]. Edwards and Newing highlights that the anticipated benefits is a factor influencing the adoption of EAI [5]. Sharif et al. [22] conclude that the evaluation of EAI project is context dependent. By understanding the organizational and technical context $\mathrm{s}$, a better definition of EAI, in terms of the scope and impacts of integration, could possibly be achieved.

Effecting enterprise-wide technology and business process change in the public sector, however, is a massive and complex undertaking [9]. The legal setting determines the functions and powers assigned to public bodies and their organizational and financial autonomy [19]. Many of the organizational functions and roles are founded in laws and regulations. These 
organizations have a legal responsibility for services provision and are free to design their own information architecture. Consequently, public sector reengineering gives much autonomy to the agencies. This autonomy has resulted in that necessary changes have not occurred, benefits are not realized and the systems have fallen into dispute and disuse [8]. The cultural setting wields an influence less direct than the legal setting, but can have equally decisive effects on the implementation of EAI [19]. Culture-based conflicts and collaboration issues may impede implementation and block innovations.

Due to the complexity of integration, the need for comprehensive understanding of the situation, and the many actors involved, practitioners are finding it difficult to manage the necessary transformation [24]. Discussions of e-government integration activities often resolve into speculations about what should be done [11]. Uncertainty about the costs and benefits of implementing an EAI approach is a central problem. The needed information about costs and benefits may be incomplete or inaccessible. Access can be limited by organizational and functional boundaries that distribute knowledge of value-added activities such that no one, including top management, has complete knowledge of the processes [3], [6]. Due to the lack of insight public organizations are still reluctant to implement it unless they are forced to do so. One of the reasons for this is that companies do not know whether and to what extent they should invest in EAI and they are unable to assess the return on these investments.

Decisions taken in one organization can have a profound influence on the activities, costs and benefits of other organizations. Often the implications for 'other organizations' are not clear, consequently these 'other' organizations do not want to invest or change their processes to profit from EAI. There are discussions about how costs are divided over and how benefits should be distributed over public agencies. These barriers impede the development of EAI. This paper describes an activity-based costing and discrete-event simulation-based approach to how a business case for EAI in e-government can be made.

\section{Research approach}

First a literature survey was performed of EAI. As there is not technology supporting all integration opportunities, we derived a systematic model to map a situation that need to be integrated on EAI technology characteristics and activity-based costing $(\mathrm{ABC})$ and discrete-event simulation was chosen to evaluate the implications of EAI by looking at information systems, business processes from a stakeholder view.

Second, case study method was chosen as the research instrument to evaluate the applicability of the evaluation approach. Case study research can be characterized as primarily qualitative and observational, using predefined research questions [30]. The paper uses data from a case-based modeling of enterprise-level integration in a municipal government setting. The results form the core of a business case for using EAI architecture, based on simulating the performance of an EAI application and identifying the resulting benefits, disadvantages, and problems.

We investigated a case study of a business counter that coordinates the efforts of various public agencies in order to deliver services. The approach taken relies on $\mathrm{ABC}$ and quantifies the costs and benefits that are to be expected in the current information processes, and when the simulated EAI application is being used. We use discrete-event computer simulation to quantify, animate, and compare the administrative processes under the current and proposed integrated process.

An analysis of the added value of the EAI mediating between public departments begins with modeling the current situation. The values of the performance indicators for the non-integrated "as is" situation represent a benchmark for comparison with the integrated situation. Next the "to be" situation with EAI is modeled. The performance differential between the situation with and without integration can be seen as a measure for the added value of EAI, provided that the models are a valid representation of the trading organizations and of their business logic.

This way of working is based on the problem solving process to handle the design of organizational change that consists of five activities, as shown in figure 1 [12][18][23].

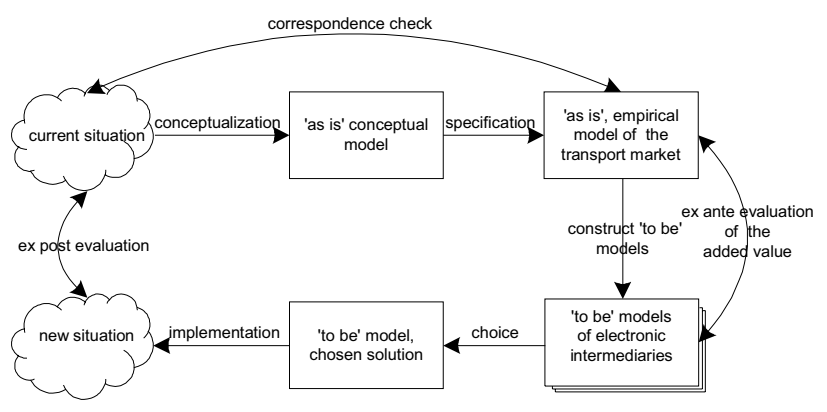

Figure 1: Way of Working

The first activity consists of examining the current situation and describe it in terms of an "as is" 
conceptual model. That conceptual model guides the collection of detailed, low-level operational and cost data on which to base the empirical ("as is") model. In the next step, the empirical "as is" model is translated into an "as is" simulation model. Next the principles of EAI and its related architecture are used to seek possible improvements to the problems or issues in the current situation (as represented by the "as is" models). A number of EAI architectures can then be worked out and used to construct "to be" models of the business processes. For each of these "to be" models the performance can be simulated and the impacts can be estimated. These estimates provide the information upon which the added value of the architecture provided can be based. In this way it is possible to evaluate different information architectures and compare the resulting performance indicators to judge the value of the business models that have been studied.

\section{Enterprise Application Integration}

The ultimate goal of EAI is to connect all the information systems between and in organizations in such a way that any application can access any other application in a transparent way. Once applications are integrated, cross-organizational processes can deliver timely and accurate information. EAI also enables improved citizen and business relationships by providing a better-integrated picture of citizens. Citizens, in turn, can interact with the organizations as an integrated business rather than individual departments. This provides for better customer satisfaction.

\subsection{EAI Technology}

There is no technology supporting all types of integration [26]. Often a portfolio of techniques is required to achieve EAI [26]. These technologies are often denoted as middleware. EAI typically combines a variety of integration technologies, such as message brokers, adapters and application servers, to build an integration architecture [16], [21], [26]. An overview of various type of middleware technology and the characteristics of the technology are presented in Table 1, based on Serian [21] and Themistocleuous et al. [26]. RPCs are Remote Procedures Calls based on a request-response relationship. MOM is Message Oriented Middleware, which is based on the exchanges of messages. TM is an abbreviation for Transaction Monitor. CORBA is the Open Management Groups Common Object Request Broker Architecture, DCOM is Microsoft's Distributed Component Object Module, and Java/Remote Method Invocation is Sun's equivalent. The characteristics are:

- Transaction is a concept that requires that a number of interactions are either committed or canceled as a whole;

- Coupling refers to the degree of tightness and dependence between systems. Two systems are tightly coupled if they are strongly dependent on each other. Changes in one system might need changes in another system;

- Standards is the use of open standard or defacto standards;

- In synchronous middleware the requester expects an immediate response of the responding party;

- Communication describes possible requester and responders interactions;

- Multi-platform and languages concerns the possibilities of enabling communication between heterogeneous systems;

- Workflow support depicts the possibility to coordinate a sequence of activities by routing messages intelligence among systems;

- The data transformation is about standard support for translating one format into another

- The use of object-oriented approach is about the invoking of objects using methods for communication with each other;

- Reliability refers to the availability of mechanism ensuring the delivery of messages.

Please note that only the basic characteristics are mapped to the middleware technology. For example, in practice often multiple RPCs are executed as a single transaction. Middleware can include a combination of RPC and transaction technologies. Web services are a special case as with the gradually expansion of the protocol stack, web services are incorporating all elements. Web-services are 'middleware agnostic', rather than replacing existing middleware solutions; web-services integrate and expand the capabilities of middleware [29]. 
Table 1: Characteristics of EAI technology

\begin{tabular}{|c|c|c|c|c|c|c|c|}
\hline Criterion & RPC & $\begin{array}{l}\text { Web- } \\
\text { services }\end{array}$ & MOM & TM & CORBA & DCOM & $\begin{array}{l}\text { Java/R } \\
\text { MI }\end{array}$ \\
\hline Transaction concept & no & no & no & yes & yes & yes & yes \\
\hline Coupling & loosely & loosely & $\begin{array}{l}\text { loosely/ } \\
\text { tight }\end{array}$ & $\begin{array}{l}\text { loosely/ } \\
\text { tight }\end{array}$ & tight & tight & tight \\
\hline Based on standards & yes & yes & no & no & yes & yes & yes \\
\hline Synchronous (s)/ asynchronous (a) & $\mathrm{s}$ & $\mathrm{s}, \mathrm{a}$ & $\mathrm{a}$ & $\mathrm{a}$ & $\mathrm{s}$ & $\mathrm{s}$ & $\mathrm{s}$ \\
\hline Communication & 1-to-1 & $\begin{array}{l}\text { 1-to-1 } \\
1-\text { to-n } \\
\text { publ-subs }\end{array}$ & $\begin{array}{l}\text { 1-to-1 } \\
1-\text { to-n } \\
\text { publ-subs }\end{array}$ & 1-to-1 & $\begin{array}{l}\text { 1-to-1 } \\
1-\text { to-n } \\
\text { publ-subs }\end{array}$ & 1-to-1 & 1-to-1 \\
\hline Multi-platform/language & yes & yes & yes & yes & yes & no & no \\
\hline Workflow support & no & yes & yes & yes & no & no & no \\
\hline Data transformation & no & yes & yes & yes & no & no & no \\
\hline Object-oriented & no & no & no & no & yes & yes & yes \\
\hline Reliability & no & no & yes & yes & no & no & no \\
\hline
\end{tabular}

\subsection{EAI benefits}

Organizations that have implemented EAI solutions have reported significant benefits that support the IT/IS evaluation process [10]. Themistocleous and Irani [25] analyzed and explained the benefits that derive from the use of EAI technology and classified them into five categories.

1. Organizational (e.g. results in more organized business processes);

2. Managerial (e.g. achieves return on investment);

3. Strategic (e.g. increases collaboration among partners);

4. Technical (e.g. achieves data, objects, and process integration); and

5. Operational (e.g. reduces cost).

Themistocleous [26] argues that all types of benefits need to be evaluated before organization should proceed with the introduction of EAI. He proposes a similar model of cost and benefits based on 1) operational (cost reductions), 2) managerial (performance increase), 3) technical (flexibility architecture), 4) strategic (customer satisfaction) and 5) organizational (effectiveness).

Organizations are often reluctant to proceed with new investments before justifying its costs and expected benefits [10], [26]. The simulation approach presented below illustrates one way such a justification can be constructed.

\section{Case: Business Counter}

This case focuses on modeling the creation of an information system to support an integrated "business counter" operation. Currently, local governments provide a business counter that provides a mix of services to businesses (described below). Providing these services requires piecemeal communication with a wide range of other public and private sector organizations. Without an integrated information system, these communications and services process are slow and costly. An EAI-based system would help overcome the deficiencies in the current architecture and separate systems. These separate architectures and systems are the results of the separation of agency programs and structures. Most public agencies are free to design their information architecture and to choose appropriate applications and software vendors. Often within agencies there is no central management and departments can buy their own applications for each process. The agencies are often stove piped with information systems organized around vertical departments.

The business counter products/services are delivered through a complex network of partnerships between public and private organizations. Entrepreneurs can request products/services using telephone, the web or by visiting the business counter. Sometimes they request products/services using the chamber of commerce. Generally, the business counter interacts with the business registry, local police departments and justice department to grant a permit. Each city has an agency responsible for operating the business counter. The agency has ongoing relationships with businesses and is responsible for service provision.

Chambers of commerce are public-private partnerships that also have relationships with businesses. They have 21 local a one central organization. The local chambers of commerce can forward product/service requests to the business counter on behalf of the requesting businesses. The control and maintenance of the business registry information system is the responsibility of the central organization of the chamber of commerce. The 
updating and maintenance of data is the responsibility of the local chambers of commerce;

Police departments are geographically fragmented and use a highly diverse collection of systems. The Justice department is a central department having one system that must be accessed in the process. A number of other departments are involved as they receive a copy of the permit after it is granted.

The business counter provides 22 structured products that involve other parties in one way or another. The processing of a liqueur product is the most complex process and involves multiple stakeholders. An overview of the business process for a liqueur permit application is shown in figure 2 .

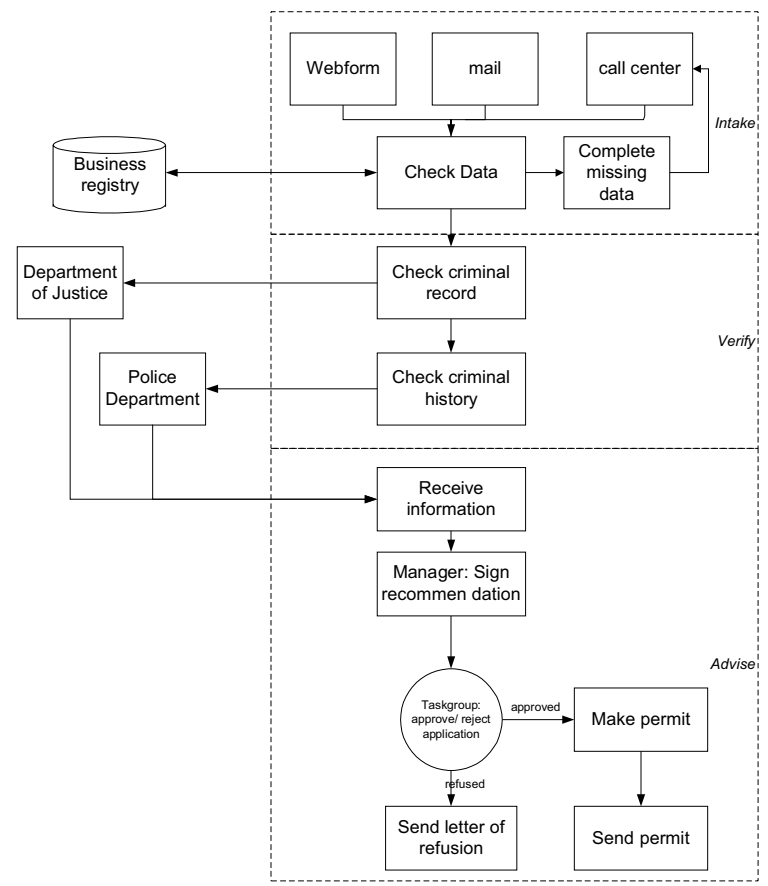

Figure 2: Business processes for liqueur permits

This process involves considerable interagency communication. An important condition for implementing EAI in such a situation is the availability of a network that interconnects the agencies. The key infrastructure is available for this, and the central government is currently implementing a Public Key Infrastructure (PKI) and a central authentication service.

\section{1. 'As is' situation}

One way of analyzing and managing the complexities involved and determining the way to achieve integration is using modeling. The initial modeling step is translating the analysis of the business process into an "as is" model of that process. A screenshot of the animation of the simulation model is shown in figure 3 .



Figure 3: Screenshot of the simulation model

\subsection{Diagnosis and solution finding}

The "as is" model reflects the current allocation of responsibilities among the actors in the process, the information used and type of messages changed.

Using the same criteria already used in Table 1 to describe EAI technology, we described the relationships between the business counter, business registry, police, and justice department. The results of this systematic analysis are shown in Table 2 . At the top the relationship between which parties are involved is shown, below the desired characteristics.

Table 2: Characteristics of Integration need

\begin{tabular}{|c|c|c|c|}
\hline Criterion & \multicolumn{3}{|c|}{ Relationships } \\
\hline From & $\begin{array}{l}\text { business } \\
\text { counter }\end{array}$ & $\begin{array}{l}\text { business } \\
\text { counter }\end{array}$ & $\begin{array}{l}\text { business } \\
\text { counter }\end{array}$ \\
\hline To & $\begin{array}{l}\text { business } \\
\text { registry }\end{array}$ & $\begin{array}{l}\text { police } \\
\text { department }\end{array}$ & $\begin{array}{l}\text { justice } \\
\text { department }\end{array}$ \\
\hline $\begin{array}{l}\text { Transaction } \\
\text { concept }\end{array}$ & $\overline{\text { no }}$ & no & no \\
\hline Coupling & loosely & loosely & loosely \\
\hline $\begin{array}{l}\text { Based on } \\
\text { standards }\end{array}$ & $\begin{array}{l}\text { yes, } \\
\text { available }\end{array}$ & $\begin{array}{l}\text { yes, } \\
\text { available }\end{array}$ & $\begin{array}{l}\text { yes, } \\
\text { available }\end{array}$ \\
\hline $\begin{array}{l}\text { Synchronou } \\
\text { s (s)/ } \\
\text { asynchronou } \\
\text { s (a) }\end{array}$ & $\mathrm{s}$ & $\mathrm{a}$ & $\mathrm{a}$ \\
\hline $\begin{array}{l}\text { Communicat } \\
\text { ion }\end{array}$ & n-to-n & n-to-n & n-to-1 \\
\hline $\begin{array}{l}\text { Multi- } \\
\text { platform/lan } \\
\text { guage }\end{array}$ & $\begin{array}{l}\text { multi- } \\
\text { platform }\end{array}$ & $\begin{array}{l}\text { multi- } \\
\text { platform }\end{array}$ & $\begin{array}{l}\text { multi- } \\
\text { platform }\end{array}$ \\
\hline $\begin{array}{l}\text { Workflow } \\
\text { support }\end{array}$ & no & no & no \\
\hline Data & no & yes & yes \\
\hline
\end{tabular}




\begin{tabular}{|l|l|l|l|}
\hline $\begin{array}{l}\text { transformati } \\
\text { on }\end{array}$ & no & no & no \\
\hline $\begin{array}{l}\text { Object } \\
\text { expertise }\end{array}$ & nigh & high & high \\
\hline Reliability & high \\
\hline
\end{tabular}

When mapping the characteristics of the EAI technology on the relationship, several EAI might be used. It seems that RPC and web services are the most suitable technologies for interaction between the business counter and the business registry.

Communication between the business counter and police and justice department needs asynchronous communication, as their systems are not continuously available. The most suitable technology seems to be message-oriented middleware (MOM). We selected two types of technology, however, this does not mean that multiple software packages are necessary. Message brokers typically support different kind of components [26].

The showing of the animation to the stakeholders resulted in the identification of a novel solution. Instead of integrating with the information systems of the agencies that want to get a copy of the permits granted, the business process might be changed. Although some organizations would require integration with their systems, others would be quite happy simply to have access to the permits on another system. The latter case has many benefits in the long term, requiring less maintenance of integrated connections. Based on the selection of these technology and change in business process the benefits are evaluated in the following subsection.

\subsection{Evaluation of the EAI}

Modeling the "to be" system depends heavily on the operation of middleware. On the one hand synchronous, event-based middleware is need for intermediating between the legacy systems of the justice department and permit department, as their legacy systems are not continuously available. On the other hand the business registry can be accessed synchronously.

For the quantitative evaluation of an integrated system, a number of performance indicators for the current system were identified in cooperation with the stakeholders involved.

1. Total lead time of a permit is the difference between the confirmation received by the requester minus the submitting of the request by the businesses to the agency;

2. The tardiness index is the ratio of the number of permits that exceed the due date of 5 weeks to the total number of requests;
3. Status information lead time is the time between the submitting of the request by a business and receiving the answer from the municipalities;

4. Utilization back-office is the total time backoffice employees are busy performing activities divided by the total working time of the employees;

5. Number of communication failures;

6. Handling time is the total working time for the whole process of providing of (dis)approving a permit;

7. Direct cost per product are the total direct costs linked to activities for processing a product requests.

The handling time and direct ordering costs are split to the three different stakeholders: business counter, police and justice departments. The lead time of the product request and status request can be considered as measure from the customer perspective. We did not include the administrative costs of the customer in the process, as our goal is to model the interagency interactions and not those with the customers.

Several cost accounting techniques exist to assess the operational cost [13]. For our purposes we need a diagnostic cost technique to evaluate the performance of "as is" processes and to compare them with alternative processes. We want to have insight into the cost of activities and the cost of products/services provided. This means that it should be possible to value single activities. The costing technique proposed by LaLonde and Pohlen [13], which is similar to the activity-based costing (ABC) technique, best fits the requirement of assigning costs to business processes. The main principle is to assign costs of resources to the products/service via activities. Effectively, this costing technique adds a process perspective to the financial perspective of the functional-based responsibility accounting systems. Cost data was collected by investigating the budgets of the public agencies. Agency representatives thereafter linked the budgets to the business processes.

The added value was assessed quantitatively by comparing the outcomes of the empirical 'as is' model with the outcomes of the 'to be' model. In the 'as is' and 'to be' models similar experiments are carried out using the same conditions. A t-test is performed with a confidence level of 5 percent to check whether the performance indicators listed in table 2 are significantly better than the current situation. The null hypothesis $\mathrm{H}_{0}: \mu_{1}=\mu_{2}$ is tested for the alternative hypothesis $\mathrm{H}_{1}: \mu_{1} \neq \mu_{2}$. The test variable is the difference between the means of both 
experiments. The test statistic is $t_{\alpha}\left(n_{1}+n_{2}-2\right)=t_{0.025}(18)=2.101$.

The results are summarized in Table 3. Most of the performance indicators show a better performance in the situation with EAI. The total working time, the working time of the police, and justice department does not decrease significantly. It seems that time needed for submitting request manually, and the extra time needed if communication fails, is a minor factor of influence on the total working. For all stakeholders the direct cost decrease.

Table 3: Quantitative simulation output for a scenario

\begin{tabular}{|c|c|c|c|c|c|c|c|}
\hline Performance indicator & Unit & $\begin{array}{l}\text { 'As is' } \\
\text { mean }\end{array}$ & st.dev. & $\begin{array}{l}\text { 'To be' (E) } \\
\text { mean }\end{array}$ & $\begin{array}{l}\text { EAl) } \\
\text { st.dev. }\end{array}$ & $\begin{array}{l}\text { Relative } \\
\text { change }\end{array}$ & Sign? \\
\hline 1. Permit lead time & days & 48.31 & 0.57 & 37.08 & 0.46 & 23.25 & $\mathrm{Y}$ \\
\hline 2. Tardiness & $\%$ & 24.50 & 0.24 & 8.59 & 0.35 & 64.94 & $\mathrm{Y}$ \\
\hline 3. Status information lead time & hrs & 15.03 & 0.43 & 1.80 & 0.58 & 88.02 & $\mathrm{Y}$ \\
\hline 4. Utilization back office & $\%$ & 87.64 & 0.14 & 73.80 & 0.13 & 15.79 & $\mathrm{Y}$ \\
\hline 5. Number of communication failures & \# & 4090 & 1.28 & 54 & 1.35 & 98.68 & $\mathrm{Y}$ \\
\hline 6. Total working time per permit & hrs & 16.93 & 0.39 & 14.78 & 0.26 & 12.68 & $\mathrm{~N}$ \\
\hline 7. Working time per product Police department & hrs & 2.58 & 0.42 & 2.43 & 0.27 & 5.85 & $\mathrm{~N}$ \\
\hline 8. Working time per product Justice department & hrs & 1.24 & 0.24 & 1.07 & 0.26 & 13.39 & $\mathrm{~N}$ \\
\hline 9. Total direct costs per product & $€$ & 1263 & 0.58 & 1045 & 0.43 & 17.23 & $\mathrm{Y}$ \\
\hline 10. Direct costs per product Police department & $€$ & 158 & 0.27 & 148 & 0.37 & 6.46 & $\mathrm{Y}$ \\
\hline 11. Direct costs per prodcut Justice department & $€$ & 79 & 0.12 & 57 & 0.28 & 28.35 & Y \\
\hline
\end{tabular}

For the costs and benefits that can be expressed directly in money, the Return on Investment (ROI) and Net Present Value (NPV) of the proposed EAI investment can be calculated. The simulation outcomes can be exported to a Microsoft Excel file and the value of the proposed scenario can be calculated by adding the investments needed and a discount rate. As a rule of thumb, government agencies commonly choose a discount rate of $15 \%$, however, the sensitivity can be calculated by adding other discount rates.

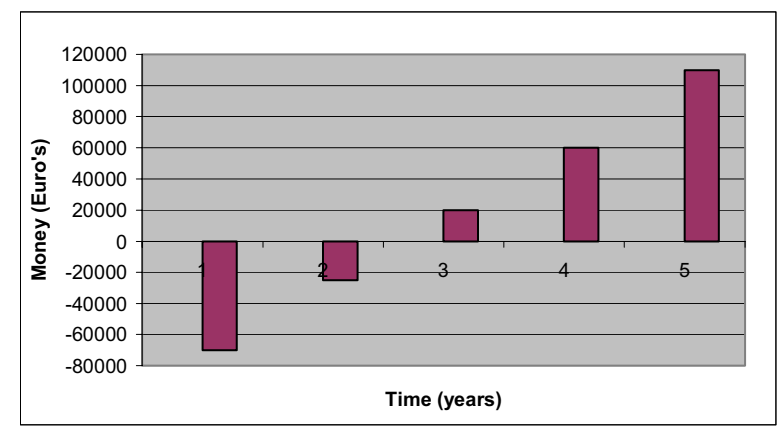

Figure 4: Example NPV calculation

The quantitative evaluation facilitates comparison on a limited number of measurable performance indicators. Of equal or greater importance is the qualitative evaluation by the persons involved. This evaluation is facilitated by the animation of the situation and the quantitative performance. Based on the model of Themistocleous [26] the benefits from the point of view of the stakeholders are presented.

1. Organizational

- Increase productivity;

- Improvement in planning as status information can be exchanged;

- New way of submitting permit copies;

- Reduction of the number of communication failures;

- $\quad$ Easy submission of reminder;

2. Managerial

- Investments can be returned within a couple of years;

- Better understanding of the cross-organizational business process;

- Easier organization of sending reminders;

- Do not integrate exception handling message;

3. Strategic

- Best practice for EAI in the public sector;

- Increase customer satisfaction

- Number of permits exceeding the legal terms decreases;

4. Technical

- Understanding of business processes;

- Clear quality and functional requirements on EAI:

- Less development risks; 
- One MOM for integrating with the justice and police department;

5. Operational

- Workload decreases;

- People can work part-time as the utilization decreases;

- Reduction of manual tasks for printing and sending of requests and answer to other organizations

\section{Discussion}

EAI is much more than just passing a message from one information system to another. It can need a complete re-design of the business logic. In our case the two tasks of sending a message to the police and justice department was integrated into one system.

\subsection{Modeling}

The results of this modeling address the cost and efficiency concerns that are found in almost every discussion about whether to make use of EAI. The cost of implementing a system can be relatively easy determined, although not accurately, whereas the benefits are much more difficult to assess and often comprise qualitative or non-tangible benefits [28]. Benefits can be unequally distributed among organizations in a network. In this case, for example, the relatively small police departments have limited benefits of EAI because the number of request per department is low.

Simulating the new technology implementation can also increase stakeholder's overall knowledge and understanding of the project. The knowledge about information and communication technology varies greatly among organizations in the case study. Smaller agencies have limited resources to devote to the implementation of EAI, may lack expertise and might have difficulties in interacting with larger agencies, because of their limited 'institutional weight'. In former projects their input might even have been ignored. A lack of knowledge within an organization can cause resistance, because efforts necessary to make use of EAI and the benefits of the use of new technology cannot be assessed by these organizations. This type of resistance may be nothing more than inertia, but can also stem from healthy suspicion and poor understanding. At the same time, smaller agencies might have a higher flexibility because of lower organizational complexity and they might be less hindered by large legacy systems. EAI evaluation should include a mapping these kinds of organizational aspects of information systems.
The modeling approach taken also facilitates communications in the early-stages of a project. Films can be made of the animation model, thus facilitating communicating of the situation to persons not directly involved in the project or who were unable to attend planning sessions. The animation explains the situation in simple, business friendly language. Animation can further facilitate communication to technical people who are responsible for implementing the middleware. The technical experts are often challenged to understand the business problems and its implications for the agencies. In this way business concerns rather then technology drive the implementation.

\subsection{Understanding}

Gaining insight in each other situation, assessing the impact and communication are crucial aspects of achieving EAI, not only to gain commitment among organization involved, but also to communicate to a national level. Politicians or public managers at a national level may be interested in the reform initiative and may create the necessary conditions for affecting EAI in the individual public organizations.

Better understanding and communication based in the modeling can enhance commitment to the needed changes. Organizations can gain insight into their own processes and those in other organizations. The models provide an overview of possible implications and consequences of an integrated implementation. The interests and requirements of all the organizations involved can be taken into account more explicitly. Employees of these organizations can participate more directly in the business engineering process, which also enhances their commitment.

The creation of commitment is a negotiation process between departments. Apart from the decisionmaking to introduce the EAI, it requires considering the degree of change a discrete moment in time and the speed of change.

\subsection{Responsibility, Accountability and transparency}

A critical issue that needs to address when introducing EAI is the establishing agreements about these allocations of responsibilities among the stakeholders. It is necessary to establish who takes the lead and is responsible for monitoring the progress and ensuring the quality of the individual performers and products/services provided. Actors must agree on how delivery times set by law can be ensured and who is accountable for failure when different services provided by external partners are orchestrated into the 
business processes. This has to be agreed upon beforehand, because orchestration cannot handle this and might demand a business-reengineering project and difficult negotiation among actors.

The legal setting determines the roles and functions assigned to public agencies and their organizational and financial autonomy. Process owners have authority over process goals and resource. They are responsible for process performance and overall interactions with customers. Compliance with strict formal regulations and the fragmentation of power across offices can make identifying and assigning process ownership practically impossible. In this test situation, each public agency had to assign a process owner. These responsibilities forced the activation of a suppliercustomer relationship between government agencies. Although the normative lead time of some permits has got a delivery time of maximal 5 weeks, there are no service level standards for the individual organization. The organizations are considering how to professionalize their customer and interagency relationship by drawing up services level agreements about normative response times, status information availability, and so on.

For governmental agencies it is especially important that their services do not fail, are transparent, and can be accounted for. Agreeing upon and monitoring service levels of the different components in a multiactor environment is very important. When for example a failure at the police department might result in the exceeding of the legal term set by law and the permit might need to be granted, even when it might .

\subsection{Generalization}

Further research might be focused on generalizing this approach to other countries by applying to several case studies. The processes analyzed are comparable in many ways to the situation in the state of New York. Obtaining government permits for business activity in New York is a similarly complex and poorly integrated process. Permits are required and issued by three levels of government in some cases (municipal, county, and state). Regulatory policies and approval processes vary by the type of business activity. Obtaining permits for alcoholic beverage sales, for example, varies according to the type of beverage, how it is dispensed (served in open containers, consumed on premises, vs. only in closed containers), whether entertainment is involved, etc. Some attempts to integrate information dissemination have been implemented, but no integrated approval processes such as the ones described here have been developed.

\section{Conclusions}

In this paper we developed an approach taking a broader understanding of EAI in government and applied this approach in a case study. We identified middleware technology by mapping characteristics of the situation and technology, and evaluated its benefits using an evaluation approach based on activity-based costing and discrete-event simulation modeling. This approach helps to identify EAI technology that could be used, and assess the value of various development paths that can be taken in implementing EAI. Our modeling approach underscored the modeling of business processes, the integration of heterogeneous information systems, and cost and benefits from various stakeholders perspective.

Implementing EAI remains a challenging problem for organizations, as it requires assessing and redesigning current business processes and shifting responsibilities. As a result costs and benefits might be unequally distributed over stakeholders. The division of benefits of EAI might help decision-makers to divide the investment and operational costs over the agencies involved.

Following the clarity about the division of costs and benefits, system development projects often underestimate the need for clear responsibilities and agreements among organizations. This should be addressed early in a change process in order to make sure who is accountable for what in case of problems, failures or other unexpected situations.

Although the expected benefits of an integrated system might be clear in advance, the introduction of EAI requires a change of business processes and procedures. Such a change requirements involve many additional costs and benefits related to involvement and commitment of the actors in the day-to-day operations. Modeling such as used in this example is a valuable tool in building this involvement and commitment. A modeling process can also generate new solutions, like providing access to the database of permits instead of sending each actor a copy of a granted permit. Simulation and animation helped to identify innovative solutions and to demonstrate the benefits.

\section{References}

[1] Allen, B.A., Juillet, L. Paquet, P. \& Roy, J. "EGovernance \& government on-line in Canada:Partnerships, people \& prospects", Government Information Quarterly, Vol. 18, 2001, pp. 93-104. 
[2] Armour, F.J., Kaisler, S.H. and Liu, S.Y. "Building an Enterprise Architecture Step by Step", IEEE IT Professional, Vol. 1, No. 4, 1999, pp. 31-39.

[3] Carter, F.J. Jambulingham, T., Gupta, V.K. \& Melone, N. "Technological innovations: a framework for communicating diffusion effects", Information and Management, Vol. 38, 2001, pp. 277-287.

[4] Dalal, N.P., Kamath, M., Kolarik, W.J. \& Sivaraman, E. "Toward an Integrated Framework for Modeling Enterprise Processes", Communications of the ACM, Vol. 47, No.3, 2004, pp. 83- 87.

[5] Edwards, P. \& Newing, R. Application Integration for E-business.

[6] Fawcett, S.E. "Using Strategic Assessment to Increase the Value-added Capabilties of Manufacturing and Logistics", Production and Inventory Management Journal, 1995, pp. 33-27.

[7] Graaf, T. (2004). De Andere Overheid. Report Ministry of the Interior and Kingdom Relations, www.andereoverheid.nl.

[8] Hackney, R.A. \& McBride, N.K. 'The efficacy of information systems in the public sector: issues of context and culture", International Journal of Public Sector management, Vol. 8, No. 6, 1995, pp. 17-29.

[9] Hazlett, S.A. \& Hill, F. "E-government: the realities of using IT to transform the public sector", Managing Service Quality, Vol. 13, No. 6, 2003, pp. 445-452.

[10] Irani, Z. and Love, P.E.D. "Developing a frame of reference for ex-ante IT/IS investment evaluation", European Journal of Information Systems, Vol. 11 No. 1, 2002, pp. 74-82.

[11] Jaeger, P.T. "The Endless Wire: E-government as global phenomenon" Government Information Quarterly, Vol. 20, pp. 323-331, 2003.

[12] Janssen, M.F.W.H.A. Designing Electronic Intermediaries. An Agent-based Approach for Designing Interorganizational Coordination Mechanisms. Delft, The Netherlands: Delft University of Technology, 2001.

[13] LaLonde, B.J. \& Pohlen, T.L. "Issues in Supply Chain Costing", The International Journal of Logistics Management, Vol. 7, No. 1, 1996, pp. 1-12.

[14] Lam, W. \& Shankararaman, V. "An Enterprise Integration Methodology", IT professional, Vol. 6, No. 1, 2004, pp. 40-48.

[15] Lee, J., Siau, K., and Hong, S. "Enterprise Integration with ERP and EAI", Communications of the ACM, Vol. 46, No. 2, 2003, 54-60.

[16] Linthicum, D. Enterprise Application Integration. Addison-Wesley, MA, USA, 1999.

[17] W. Mendenhall, and T. Sincich, Statistics of the Engineering and Computer Sciences. Collier Macmillan, Canada, 1988.
[18] Mitroff, F. Betz, L.R. Pondy, and F. Sagasti, "On managing science in the systems age: Two schemas for the study of science as a whole systems phenomenon", Interfaces, Vol. 4, No. 3, 1974, pp. 46-58.

[19] Ongaro, E. "Process management in the public sector: The experience of one-stop shops in Italy", International Journal of Public Sector Management, Vol.17, No. 1. 2004, pp. 81-107.

[20] Peristera, V. and Tarabanis, K. "Towards an enterprise architecture for public administration using a top-down approach", European Journal of Information Systems, vol. 9, 2000, pp. 252-260.

[21] Serian, D. Middleware and Enterprise Application Integration. Springer Verlag, London, 2002.

[22] Sharif, A.M. Elliman, T. Love, P.E.D. \& Badii, A. "Integrating the IS with the enterprise: key EAI research challenges", The Journal of Enterprise Information Management, Vol. 17, No. 2., 2004, pp. 164-170.

[23] Sol, H.G. Simulation in Information Systems Development. Groningen, The Netherlands: University of Groningen, 1982.

[24] Tan, C.W. \& Pan, S.L. "Managing e-transformation in the public sector: an e-government study of the Inland Revenue Authority of Singapore", European Journal of Information Systems, Vol. 12, 2003, pp. 269-281.

[25] Themistocleous, M \& Irani, Z. "Benchmarking the benefits and barriers of application integration", Benchmarking: An International Journal, Vol. 8, No. 4, 2002, pp. 317-331.

[26] Themistocleous, M. "Justifying the decisions for EAI implementations: a validated proposition of influential factors", Journal of Enterprise Information Management, Vol. 17 No. 2, 2004, pp. 85 - 104.

[27] Themistocleous, M., Irani, Z. \& Love, P.E.D. "Evaluating the integration of supply chain information systems: A case study", European Journal of Operational Research, Vol. 159 No. 2, 2004, pp. 393-405.

[28] Turben, E., King, D., J.K.Lee \& Viehland, D. (2003). Electronic Commerce 2004: A Managerial Perspective. Prentice Hall, 2003.

[29] Vinoski, S. "Where is middleware?", IEEE Internet Computing, Vol. 6, No. 2, 2002, pp. 83-85.

[30] Yin, R.K., Case Study Research: Design and methods. Sage publications, Newbury Park, California, 1989. 